\title{
O TESOURO DO LÉXICO PATRIMONIAL GALEGO E PORTUGUÉS NO MARCO DO ESPAZO LINGÜÍSTICO GALEGO-PORTUGUÉS (PE E PB)
}

Marta Negro Romero

Instituto da Lingua Galega, Universidade de Santiago de Compostela doi:10.17075/tucmeg.2015.005 

CAstro, O. / M. LiÑEIRA (eds.) (2015): Trama e urda. Contribucións multidisciplinares desde os estudos galegos, Santiago de Compostela, Consello da Cultura Galega. doi:10.17075/tucmeg.2015.

\section{INTRODUCIÓN ${ }^{33}$}

O Tesouro do léxico patrimonial galego e portugués (de aquí en diante Tesouro) é un proxecto internacional no que participan investigadores galegos, portugueses e brasileiros baixo a coordinación da profesora Rosario Álvarez Blanco do Instituto da Lingua Galega da Universidade de Santiago de Compostela. O Tesouro naceu coa intención de crear un corpus informatizado que reunise material léxico vinculado coa cultura tradicional, especialmente o vinculado con tradicións e saberes que xa desapareceron ou están a piques de desaparecer debido a mudanzas sociais e culturais.

O resultado deste proxecto é un banco de datos, de acceso libre desde febreiro de 2014 a través do portal web do Instituto da Lingua Galega, ${ }^{34}$ no que se rexistran e integran materiais lexicográficos con referenciación xeográfica relativos ao dominio galego, portugués europeo e portugués brasileiro. Os datos son extraídos de obras moi heteroxéneas: corpora obtidos en traballos de campo, materiais dispersos en obras dialectais, vocabularios de falas, atlas, etc., moitas delas inéditas e de moi difícil acceso, polo que outro dos obxectivos do Tesouro, ademais do de preservar numeroso léxico dialectal, é o de poñer todos estes materiais a disposición da comunidade científica e do público xeral.

$\mathrm{Na}$ aplicación de consulta do proxecto o usuario ten á súa disposición todas as voces rexistradas nas distintas fontes, xunto á información lexicográfica e bibliográfica, ademais da cartografía xerada automaticamente onde se amosa a distribución territorial de cada forma nos tres dominios lingüísticos obxecto de estudo. É frecuente que tamén se recollan exemplos de uso, refráns, cancións, etc., para alén de fotografías e debuxos. Outra información que se ofrece, resultado da aplicación de diversas metodoloxías lingüísticas á heteroxeneidade dos materiais, é o lema, a categoría gramatical e a clasificación semántica. Deste

33 Este artigo inscríbese dentro do proxecto de investigación Tesouro do léxico patrimonial galego e portugués Banco de datos electrónico (corpus galego) e cartografía automática (FFI2009-12110), financiado pola Secretaría de Estado de Investigación (Ministerio de Ciencia e Innovación). Queremos agradecerlles a Rosario Álvarez e Ernesto González a súa valiosa axuda ao longo do proceso de elaboración deste artigo. Tamén queremos expresarlle a nosa gratitude aos restantes membros do equipo do proxecto cos que compartimos traballo.

$34 \mathrm{O}$ Tesouro pode consultarse en http://ilg.usc.es/Tesouro/. 
CAStro, O. / M. LiÑEIRA (eds.) (2015): Trama e urda. Contribucións multidisciplinares desde os estudos galegos, Santiago de Compostela, Consello da Cultura Galega. doi:10.17075/tucmeg.2015.

xeito, o usuario pode obter toda a información lexicográfica a través de buscas por un lema (por exemplo, galego e portugués pálpebra), por unha variante (por exemplo, pálpera), por un clasificador semántico (se seleccionamos, por exemplo, o clasificador 3.2.5 obteremos todo o léxico integrado na base relacionado coa castaña), por unha categoría gramatical (por exemplo, adverbio) ou pola localización (pódese escoller que apareza o léxico dun dos territorios, de dous deles ou dos tres).

$\mathrm{O}$ feito de que o Tesouro presente de maneira conxunta e integrada os datos léxicos procedentes das variedades populares galegas, portuguesas e brasileiras convérteo nun instrumento privilexiado para a realización de estudos lingüísticos, sincrónicos e diacrónicos, en diversas áreas: lexicografía, terminoloxía, etimoloxía, onomástica, norma lingüística e variación, dialectoloxía, morfoloxía, fonética e fonoloxía, estratigrafía, etc. Pero esta ferramenta non só é de interese para a lingüística, xa que os datos lingüísticos e extralingüísticos (fotografías, debuxos, explicacións sobre costumes e usos) que se ofrecen son de grande axuda tamén para outras disciplinas como a etnografía, a historia e a xeografía.

No presente artigo centrarémonos nalgunhas das utilidades do Tesouro para a realización de estudos centrados no espazo lingüístico galego e portugués (tanto portugués europeo como portugués do Brasil), posto que unha descrición pormenorizada do proxecto e da metodoloxía empregada podémola atopar xa noutros artigos. ${ }^{35}$ É importante sinalar que este traballo só ten por obxectivo describir algúns dos aproveitamentos que ofrece o Tesouro; non presentamos, xa que logo, un estudo etimolóxico, lexicográfico ou xeolingüístico do léxico utilizado a modo de exemplificación, xa que que excederiamos considerablemente os límites atribuídos a este traballo. Non obstante, estes materiais poderán servir de base a outros estudos onde serán analizados con detemento. Antes de sinalar algunhas das utilidades da ferramenta, describiremos as fontes que integran o corpus.

\section{FONTES}

O Tesouro do léxico patrimonial galego e portugués está integrado por materiais léxicos localizados xeograficamente no dominio lingüístico galego e portugués. Aínda que inicialmente se limita ao portugués europeo edo Brasil, o proxecto podería ampliarse con materiais doutros territorios lusófonos ou incluso doutros dominios lingüísticos, xa que tanto a metodoloxía

35 Pódense consultar os artigos citados na bibliografía de Álvarez e Sousa (2013) e de Álvarez Blanco et (2009), así como o de Ernesto González Seoane publicado neste mesmo volume. 
CAStro, O. / M. LiÑEIRA (eds.) (2015): Trama e urda. Contribucións multidisciplinares desde os estudos galegos, Santiago de Compostela, Consello da Cultura Galega. doi:10.17075/tucmeg.2015.

lingüística empregada para o tratamento da información como a aplicación de consulta son extrapolables a materiais léxicos doutras linguas. Podemos distinguir a seguinte tipoloxía de fontes:

a) Monografías etnolingüísticas.

Unha parte moi significativa dos materiais constitúena traballos académicos de diverso tipo, tanto teses doutorais e memorias de mestrado como traballos académicos realizados nos cursos de doutoramento e nos últimos anos da licenciatura, revisados por profesores universitarios e defendidos perante un tribunal. Por tanto, as obras son bastante heteroxéneas en canto á extensión, profundidade da investigación, calidade, modo de presentación da información e análise.

A maioría das obras introducidas nestes momentos na base axústanse a esta tipoloxía. De feito, das 11 obras brasileiras subidas á aplicación, 9 son teses e memorias de mestrado; das 55 obras portuguesas, 54 son memorias de licenciatura; e das 49 obras galegas, 39 son teses, memorias de licenciatura e traballos académicos. ${ }^{36}$ Ademais, moi poucos traballos están publicados total ou parcialmente como monografías ou artigos (só 9 das obras portuguesas e 4 das galegas o están). Por tanto, o Tesouro, como xa sinalamos na introdución, axuda á conservación e dispoñibilización de todos estes materiais, moitos inéditos, dos que ás veces só se conservan unha ou dúas copias en formato papel, non sempre depositadas en bibliotecas universitarias (polo tanto, só accesibles a través do propio autor ou dalgún membro do tribunal avaliador).

Dentro das monografías encontramos, por un lado, monografías redactadas como a de Álvarez (1974) e, polo outro, monografías que inclúen un glosario, que pode estar organizado alfabeticamente, como en Netto (1949), ou combinar os procesos de elaboración dun dicionario ideolóxico cos de elaboración dun dicionario alfabético, como en Morandeira (1969). É frecuente, ademais, que se centren na fala dunha localidade, concello ou rexión (Maia 1965, Castro 1986, Rodríguez 1974, etc.) e, nalgúns casos, recollen o léxico dunha área para unha actividade determinada, como a apicultura (Sozim 1992), a pesca (Carrancho 1969), a olaría (Costa 2012) ou as salinas (Amorim 1988). Por último, algunhas delas ocúpanse da influencia doutras linguas na fala dunha rexión (Borges 1954).

b) Bases de datos de atlas lingüísticos e enquisas dialectais.

Estas bases de datos inclúen non só o material que será cartografado, senón tamén outro tipo de información (debuxos, fotografías, cantigas, refráns...), que moitas veces non pode ser presentada na publicación impresa e que agora poderá ser incorporada ao Tesouro.

36 Estes datos, consultados en xullo de 2014, son provisionais, xa que se seguen a introducir de forma constante novos materiais na base do Tesouro. Para unha consulta actualizada do corpus, pódese visitar a sección «corpus» na páxina do proxecto xa mencionada anterioremente, en http://ilg.usc.es/Tesouro/. 
CAStro, O. / M. LiÑEIRA (eds.) (2015): Trama e urda. Contribucións multidisciplinares desde os estudos galegos, Santiago de Compostela, Consello da Cultura Galega. doi:10.17075/tucmeg.2015.

Os centros de investigación e equipos participantes de Portugal dispoñen de datos do Atlas Lingüistico de la Península Ibérica (ALPI) recollidos por Aníbal Otero, Armando Nobre de Guzmão e Luís F. Lindley Cintra en 1930-36 e completados en 1947-54; do Atlas linguístico do litoral português (ALLP), coordinado por Gabriela Vitorino e do que xa se publicou a parte correspondente á súa tese (1987); as bases de datos do Atlas Linguístico-Etnográfico dos Açores (ALEAç), en curso de elaboración no Centro de Linguística da Universidade de Lisboa, con datos recollidos entre 1979 e 1996; e os datos dos cadernos e gravacións do Atlas Linguístico-Etnográfico de Portugal e da Galiza (ALEPG), provenientes das enquisas realizadas fundamentalmente por Manuela Barros Ferreira, João Saramago, Luisa Segura e Gabriela Vitorino entre 1973 e 2004. Cabe destacar, pola súa relevancia, o Inquérito Linguístico por correspondencia iniciado por Manuel de Paiva Boléo en 1942, que se conserva na Faculdade de Letras da Universidade de Coimbra.

Os investigadores galegos contan, ademais de cos materiais galegos do ALPI, cos materiais do Atlas Lingüistico Galego ( $A L G a$ ), elaborado a partir das enquisas realizadas por Rosario Álvarez, Francisco Fernández Rei e Manuel González entre 1974 e 1977, e do que xa hai cinco volumes publicados; da Nomenclatura de la fauna y flora marítimas de Galicia de Carmen Ríos Panisse; e co léxico recollido para a parte galega do Léxico de los marineros peninsulares, proxecto dirixido por Manuel Alvar.

Aínda que as enquisas do Atlas Linguístico do Brasil están en curso, os equipos brasileiros contan cos datos dun bo número de atlas rexionais. Nestes momentos están incorporados ao corpus do Tesouro os materiais do Atlas Linguístico da Paraíba (ALPB) e do Atlas Linguístico do Estado do Ceará (ALECE), ambos con dous volumes xa publicados. Polo de agora, estes son os dous únicos atlas introducidos dos tres dominios lingüísticos, xa que está previsto que os materiais procedentes das bases de datos dos atlas sexan incorporados en último lugar.

De todos os xeitos, para poder mostrar mellor a utilidade do Tesouro no estudo do complexo lingüístico galego-portugués-brasileiro, introducimos os datos relativos ao concepto tornecelo «parte saínte dos ósos que forman a articulación da perna co pé» contidos nos seguintes atlas: $A L G a, A L E P G,{ }^{37} A L P B, A L P I,{ }^{38}$ Atlas Linguístico de Mato Grosso do Sul (ALMS), Atlas Linguístico da Mesorregião Sudeste de Mato Grosso (ALMESEMT), Atlas Linguístico do Paraná (ALPR), Atlas Linguístico de Sergipe (ALS) e Atlas Linguístico Sonoro do Pará (ALISPA).

\footnotetext{
${ }^{37}$ Os datos do $A L E P G$, aínda inéditos, foron facilitados polo profesor João Saramago.

${ }^{38}$ Os datos do $A L P I$ foron proporcionados polo profesor Xulio Sousa, xa que aínda non están accesibles para a súa consulta.
} 
CAstro, O. / M. LiÑEIRA (eds.) (2015): Trama e urda. Contribucións multidisciplinares desde os estudos galegos, Santiago de Compostela, Consello da Cultura Galega. doi:10.17075/tucmeg.2015.

c) Outros materiais con léxico dialectal.

No dominio do galego e do portugués europeo existen diversos traballos que estudan a cultura local desde unha perspectiva antropolóxica ou etnolingüística. Podemos citar as obras pioneiras da dialectoloxía galega, da primeira metade do século XX, da autoría de diversos filólogos alemáns como Ebeling, Krüger e Schneider, cuxa obra xa está incorporada á base do Tesouro, así como os traballos dos investigadores do Seminario de Estudos Galegos (Xaquín Lorenzo, Fermín Bouza Brey, etc.).

Hai tamén numerosos traballos que recollen léxico dialectal publicados por autores menos coñecidos en publicacións locais ou comarcais ou en páxinas web que usualmente no son consideradas nas bibliografías científicas. Nestes momentos contamos no corpus cos datos extraídos de catro blogues onde se rexistra o léxico de Brumoso (López et al. 2011) e Porto (Blanco 2012), ambas localidades zamoranas, A Illa de Arousa (Domínguez 2012) e Codosedo, Sarreaus (Chao 2012).

\section{LIÑAS DE EXPLOTACIÓN DO TESOURO DO LÉXICO PATRIMONIAL GALEGO E PORTUGUÉS}

Procederemos a exemplificar algunhas das posibilidades que ofrece o Tesouro a través de dous conceptos do corpo humano: o nocello ou tornecelo e a úvula. Decidimos traballar co campo semántico do corpo humano porque nos garantía poder encontrar información nos materiais portugueses, brasileiros e galegos. Se escolleramos outro campo, poderiamos non atopar denominacións para un concepto nun dos dous lados do Atlántico (ben no Brasil, ben en GaliciaPortugal), debido ás diferenzas xeográficas, climáticas, botánicas, etc. existentes.

\subsection{Análise da distribución das diversas denominacións existentes para un concepto}

O Tesouro posibilita presentar conxuntamente a distribución de cada variante ou elemento léxico dentro do complexo lingüístico galego-portugués-brasileiro, polo que permite evidenciar a existencia de «descontinuidades» na distribución territorial actual de determinadas solucións e, deste xeito, deitar luz sobre os procesos de emerxencia, propagación, mudanza e decadencia que tiveron e teñen lugar no interior deste complexo lingüístico. Nesta liña cobra especial importancia a expansión areal de formas léxicas e variantes morfemáticas, non só reavaliando o papel da fronteira no espazo constitutivo, senón analizando a 
CAStro, O. / M. LiÑEIRA (eds.) (2015): Trama e urda. Contribucións multidisciplinares desde os estudos galegos, Santiago de Compostela, Consello da Cultura Galega. doi:10.17075/tucmeg.2015.

difusión no vasto e complexo espazo brasileiro, onde son usuais voces que hoxe, no contexto das variedades europeas, pasan por caracteristicamente galegas.

A seguir, veremos cales das variantes recollidas na base do Tesouro para designar o tornecelo son comúns aos tres territorios, a dous deles ou exclusivas dun. Hai que ter presente que no momento de concluír este artigo contamos con corenta e nove obras de Galicia, cincuenta e cinco de Portugal e once do Brasil introducidas na base. Debido a que aínda non posuímos información de todo o territorio brasileiro, galego e portugués, os mapas de distribución das diversas denominacións que se ofrecen son provisionais; cando dispoñamos dun maior volume de datos para os tres territorios, a distribución que presentamos poderá variar. Debemos sinalar que, nestes momentos, aínda non se inseriu na base o lema común a galego e portugués. Tampouco está incorporado o xeosinónimo de referencia, é dicir, a variante baixo a que se agruparán todas as denominacións existentes para determinado concepto; deste xeito, baixo o lema tornozelo, por exemplo, atoparemos nocello, artello, tornecelo, mocotó, rejeito...

a) Denominacións comúns a Galicia, Portugal e Brasil.

As voces tornecelo, tornozelo e variantes aparecen nos tres dominios lingüísticos, aínda que a súa extensión é desigual, como se pode observar na Fig. 1. Namentres en Brasil esta denominación se distribúe por áreas distantes entre si, en Galicia concéntrase nunha área ao sur e en Portugal principalmente no norte. Poder mostrar conxuntamente os datos galegos e portugueses, grazas á cartografía xerada automaticamente pola aplicación, permítenos visualizar a existencia dun contínuum entre Galicia e Portugal, que deseña unha área máis ou menos compacta de tornecelo.

Outra das denominacións común aos tres territorios é canela. En Galicia e Portugal canela só se recolle co significado de «tornecelo» en Curtis e no distrito de Bragança respectivamente, namentres en Brasil atopamos seis rexistros en Mato Grosso do Sul. O feito de rexistrar datos nas tres áreas condúcenos a desbotar a idea de estar perante unha rareza local do galego ou do portugués, xa que se só tiveramos acceso á información galega ou portuguesa, poderiamos pensar que o entrevistador entendeu mal ou o informante malinterpretou o que se lle estaba a preguntar. Este podería ser un exemplo de polixénese, isto é, en cada territorio xurdiu a palabra de forma independente, ou un caso de migración de palabras, que quedaría oculto se non fose pola información que nos ofrece o Tesouro.

Por outra parte, canela úsase principalmente para designar o óso que vai do pé ata o xeonllo, pero é frecuente, como explicaremos máis adiante, que exista metonimia espacial entre partes do corpo próximas entre si, e canela «tornecelo» probablemente sexa un exemplo disto. Tamén pode ter relación coa 
CAStro, O. / M. LiÑEIRA (eds.) (2015): Trama e urda. Contribucións multidisciplinares desde os estudos galegos, Santiago de Compostela, Consello da Cultura Galega. doi:10.17075/tucmeg.2015.

canela do fío «peza cilíndrica das máquinas de tecer na que vai enrolado o fío», isto é, estariamos entón ante un exemplo de uso metafórico. É dicir, verificamos a existencia de procesos metafóricos e metonímicos coincidentes nos tres dominios.

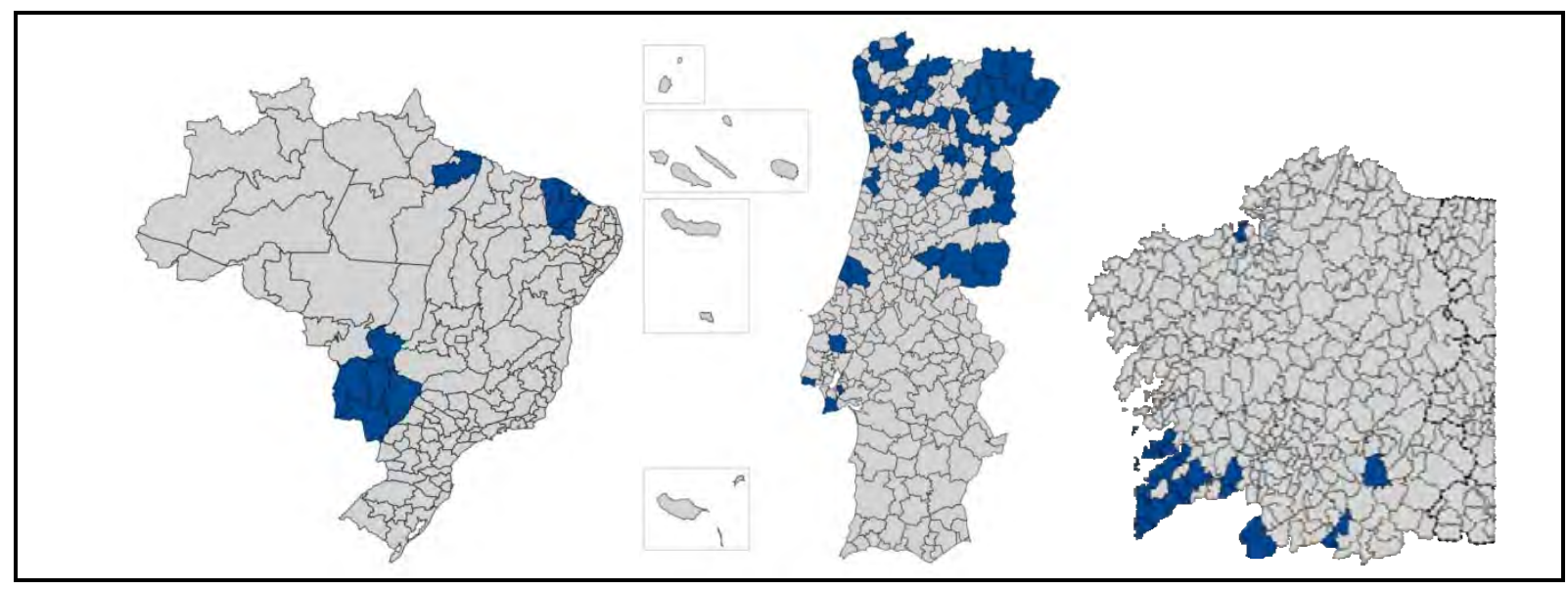

Fig. 1. Tornozelo, tornecelo

b) Denominacións comúns a Galicia e Portugal.

Galicia e Portugal comparten as denominacións artello, artelho; nortello, nortelho e variantes. Artelho ten maior presenza na metade sur do territorio portugués, namentres nartelho só se recolle en Mafra. En vista da súa distribución territorial (véxase Fig. 2) e dos noventa e cinco rexistros do Tesouro, resulta curioso que no dicionario Houaiss se especifique que a forma artelho é de «uso impróprio». En Galicia, artello e nortello recóllense no territorio coruñés limítrofe coa provincia de Pontevedra, na provincia de Pontevedra, a excepción do extremo sur, e na provincia de Ourense menos na área máis oriental (véxanse Fig. 2 e 3). Polo tanto, artello e nortello forman en Galicia unha área, complementaria da de tornecelo, dividida en dúas subáreas, e en Portugal artelho concéntrase no sur, en distribución complementaria da área de tornozelo. Á vista da distribución que ofrecen os mapas de artello, nortello e tornecelo en Galicia e Portugal, podemos pensar que tornecelo veu romper o contínuum existente entre estes dous dominios lingüísticos para a voz artello e variantes, xa que esta forma se sitúa ao norte e ao sur da área de tornecelo.

Outra voz común a ambos os territorios é noz, cun único rexistro nos concellos galegos da Coruña e Oleiros e no municipio portugués de Alvaiázere. No concello galego de Ares tamén se recolle a locución noz do pé. Este é outro exemplo de que se non contaramos coa distribución dos dous dominios lingüísticos, concluiriamos que estabamos perante unha rareza local, pero ao rexistrase a palabra en lugares distantes entre si, debemos xa facer unha análise máis profunda. 
CAstro, O. / M. LiÑEIRA (eds.) (2015): Trama e urda. Contribucións multidisciplinares desde os estudos galegos, Santiago de Compostela, Consello da Cultura Galega. doi:10.17075/tucmeg.2015.

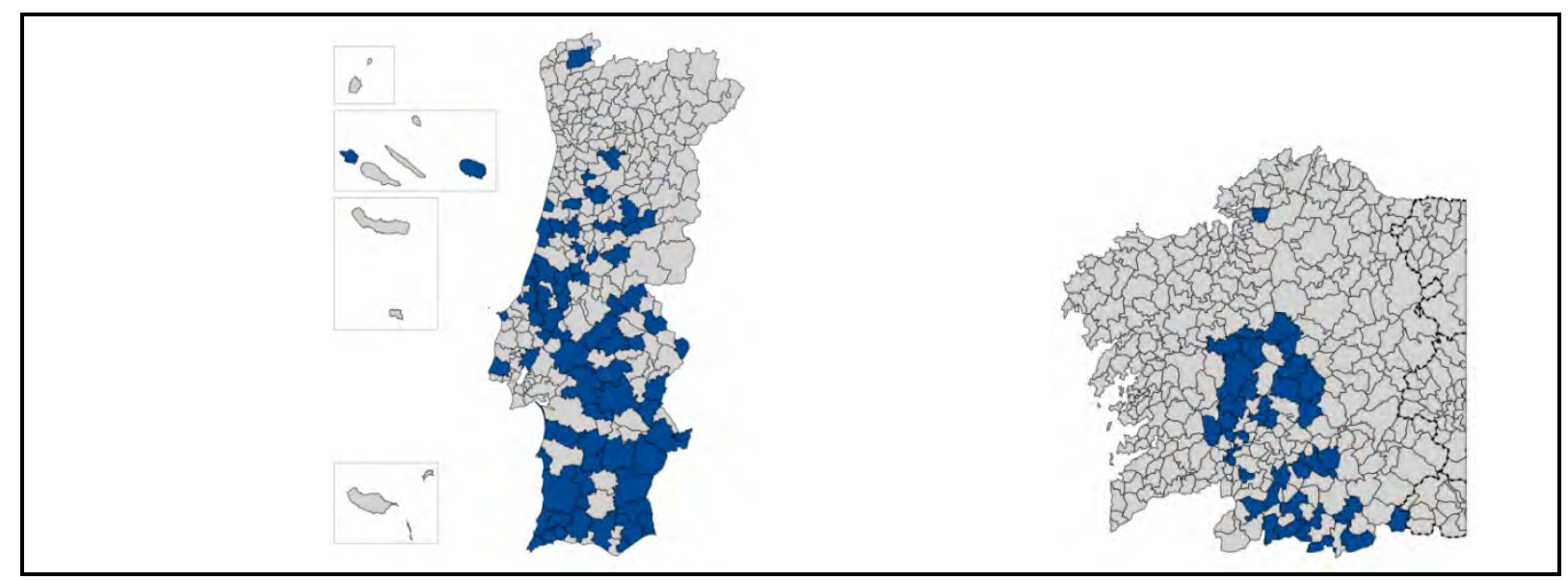

Fig. 2. Artelho, artello

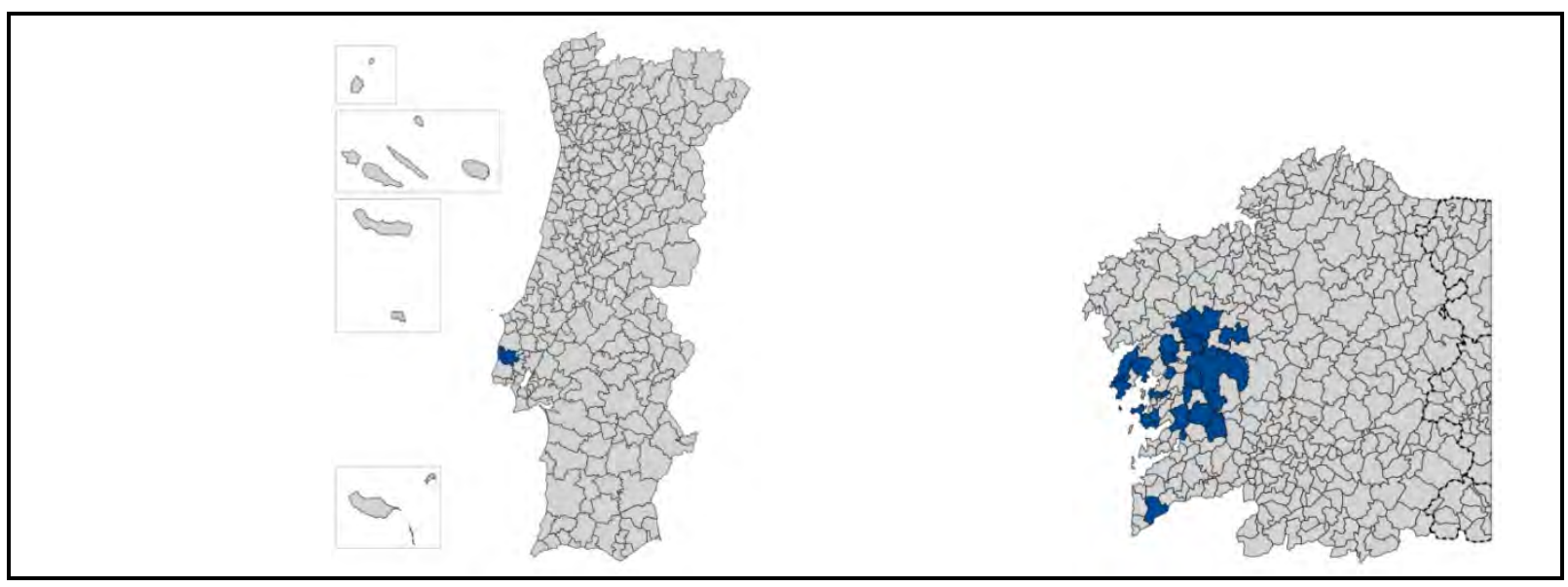

Fig. 3. Nartelho, nortello

c) Denominacións comúns a Galicia e Brasil.

Nobelo, co significado de «nocello», só se rexistra en Valdoviño (Galicia), e novelo da junta, no leste de Mato Grosso do Sul (Brasil). ${ }^{39}$ Cotobelo tamén se rexistra só nun punto da xeografía galega (Arbo), e en Brasil aparece cotovelo disperso por diversos puntos do territorio (Fortaleza, leste de Sergipe, suroeste de Mato Grosso do Sul e sur e noroeste do Ceará). Estamos de novo ante dúas formas moi pouco frecuentes que se autorizan mutuamente na distancia. Ademais, nobelo significa «bóla de fío enrolado» tanto en galego como en portugués, polo que temos o mesmo proceso metafórico de extensión de significado nas dúas linguas. Tornobelo, resultado do cruzamento entre tornecelo e nobelo, rexístrase nos concellos galegos de Lobios,

${ }^{39}$ Nobelo, como explica Coromines (1989), deriva do antigo lobellum, e este de GLOBELLUM, polo que a grafía galega con $<\mathrm{b}>$ se corresponde coa etimolóxica, a diferenza do que sucede en portugués. Se se tratase dun desenvolvemento consonántico a partir de $<_{0}>$ en hiato, entón teriamos novelo tanto en galego como en portugués, como sucede en devecer, dovecer, procedentes de doecer. 
CAStro, O. / M. LiÑEIRA (eds.) (2015): Trama e urda. Contribucións multidisciplinares desde os estudos galegos, Santiago de Compostela, Consello da Cultura Galega. doi:10.17075/tucmeg.2015.

Entrimo e Cualedro (Schneider 1938), e tornovelo, nun punto brasileiro no pantanal sur de Mato Grosso (véxase Fig. 4). Esta distribución lévanos a pensar de novo nun caso de polixénese ou de migración de palabras, e fainos desbotar a idea de estar ante unha creación idiolectal ou microlectal.

Unha última denominación compartida polos dous dominios lingüísticos, como podemos ver na Fig. 5, é tobillo, tovilho. En Galicia, o castelanismo está estendido por todo o territorio, pero debemos destacar a presenza de tovilho no suroeste de Mato Grosso do Sul, o cal podería ser tamén un castelanismo adoptado pola influencia do español no estados do sur do Brasil.

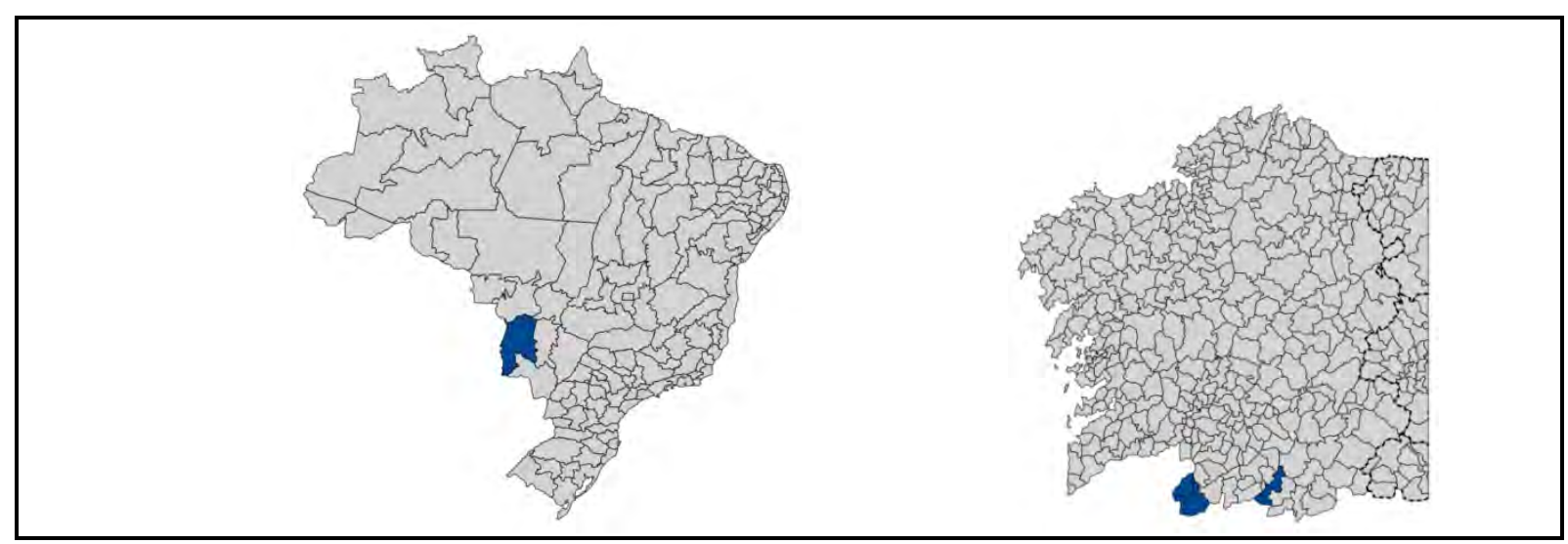

Fig. 4. Tornovelo, tornobelo

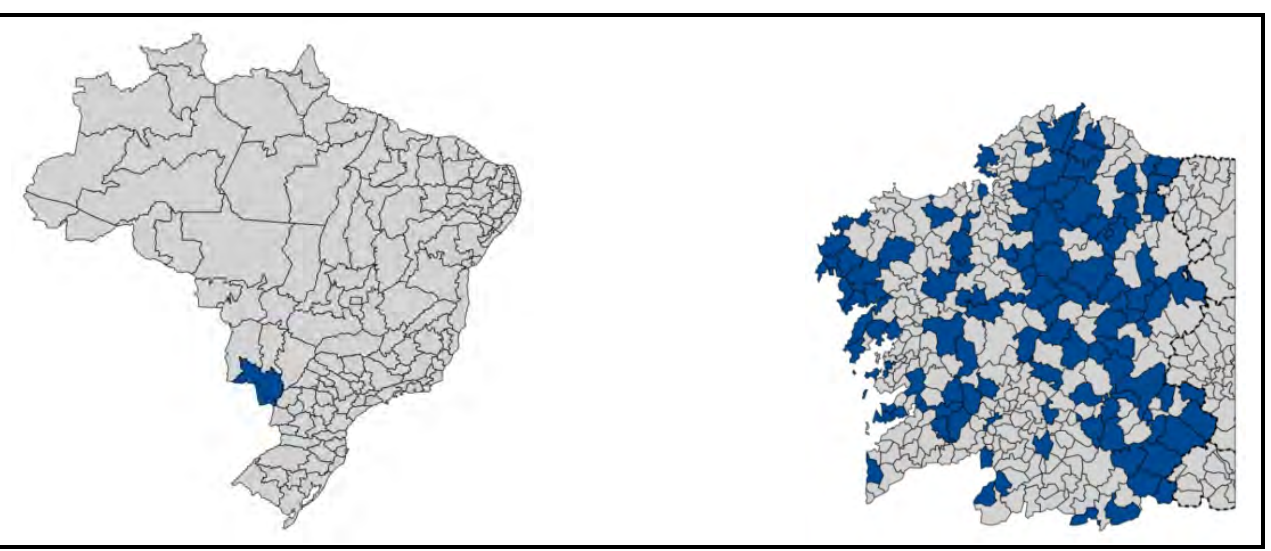

Fig. 5. Tovilho, tobillo

d) Denominacións exclusivas de Galicia.

Nocello, nocello do pé e variantes ${ }^{40}$ só se rexistran en Galicia nunha área compacta no centro da provincia da Coruña (véxase Fig. 6), e tocelo

\footnotetext{
${ }^{40}$ Coromines (1989) indica que nocelo, nocello son o resultado do cruzamento de noelo e tornecelo, pero á vista dos datos cos que contamos, discordamos co autor catalán. Por un lado, tornecelo non se rexistra na área de noelo, e, polo outro, é moito máis común a voz nocello ca nocelo, polo que parece pouco probable que o sufixo - ello se crease por analoxía co - elo de tornecelo. Na base destas voces e de noelo poden estar tanto noz como
} 
CAStro, O. / M. LiÑEIRA (eds.) (2015): Trama e urda. Contribucións multidisciplinares desde os estudos galegos, Santiago de Compostela, Consello da Cultura Galega. doi:10.17075/tucmeg.2015.

concéntrase nunha pequena área contigua da Costa da Morte (Fig. 7). Noelo e noello son voces propias do galego exterior, do extremo oriental da provincia de Lugo e dos concellos coruñeses de Sobrado, Boimorto, Aranga, Pontedeume, A Capela, Mazaricos, Moeche, Valdoviño, Cedeira e Cariño (véxase Fig. 8); polo que xunto a nocello e tocelo constitúen unha área conformada por subáreas. Debemos sinalar que algúns informantes indican que o noelo só é o óso que sobresae do tornecelo. Por último, encontramos os sintagmas pescozo do pé, distribuído polos concellos de Aranga, Tordoia, Touro e Ribeira; e tornillo do $p e ́$, cun único rexistro en Santiago de Compostela.

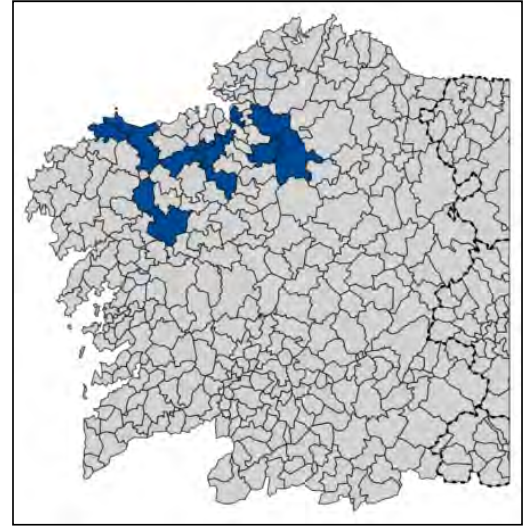

Fig. 6. Nocello

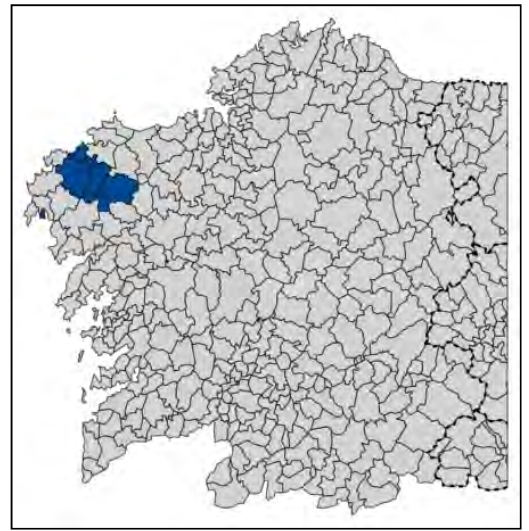

Fig. 7. Tocelo

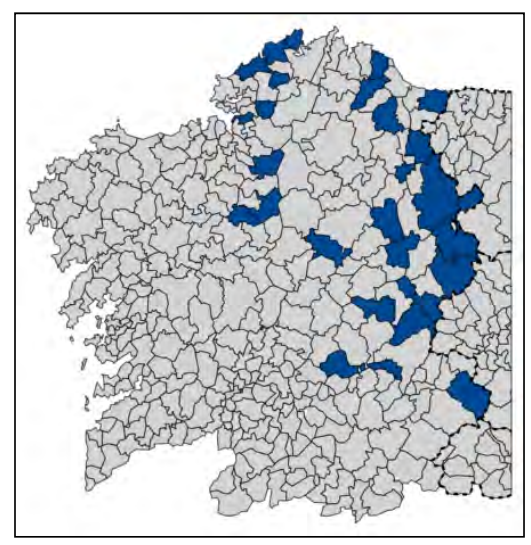

Fig. 8. Noelo

e) Denominacións exclusivas de Portugal.

Só rexistramos a voz residual covilhão como denominación exclusiva do portugués en Sousel, o que contrasta coa grande variedade de denominacións do territorio brasileiro.

nó, sobre todo se temos en consideración que estas dúas palabras serven para denominar outras partes do corpo de forma similar á que estamos a tratar, como o óso do pulso e o vulto que forma a larinxe na parte anterior do pescozo dos homes. 
CAstro, O. / M. LiÑEIRA (eds.) (2015): Trama e urda. Contribucións multidisciplinares desde os estudos galegos, Santiago de Compostela, Consello da Cultura Galega. doi:10.17075/tucmeg.2015.

f) Denominacións exclusivas do Brasil.

O primeiro que chama a nosa atención, sobre todo en relación aos outros dous dominios, é a grande variedade de denominacións exclusivas do Brasil para designar o tornecelo. As tres variantes de maior extensión territorial e con maior número de rexistros na base, de entre todas as denominacións exclusivas, son mocotó (Fig. 9), rejeito (Fig. 10), junta e junta do pé (Fig. 11), con presenza nos estados do Ceará, Mato Grosso do Sul, Paraíba e Sergipe. No Ceará e Mato Grosso do Sul encontramos varios testemuños de calcanhar e as súas variantes. Ao igual que sucedía con canela, estamos perante un caso de metonimia espacial, pero debemos destacar o feito de que neste caso só se dá en Brasil. Tamén contan con varios rexistros garrão e garrão da perna, formas matogrossenses do sur. Outras denominacións con presenza en máis dun estado son machim, localizada en Borborema (Paraíba), no leste sergipano e no noroeste cearense; e mondongo, mondongo do pé e mondrongo, presentes en Sergipe e en Borborema (Paraíba).

Debemos destacar a riqueza dos sintagmas constituídos por osso + de ou do, da + substantivo ou osso + adxectivo: osso da miséria, ossinho da miséria, osso do gostoso, ossinho doído, ossim do vintém, osso-da-madrugada, osso-docacaná, osso da canela, osso-da-risada, ossim-da-risada, osso-da-joaquina, osso-da-maria-joaquina ou Maria-joaquina e osso-de-são-severino. Estes sintagmas rexístranse residualmente nos estados do Ceará e da Paraíba, a excepción de ossinho-da miséria e osso-da-miséria, que aparecen en Mato Grosso do Sul e contan con varios rexistros.

Outras designacións só teñen un único rexistro: batata da perna, peador, pendão (Mato Grosso do Sul); joaninha, tronco (Sergipe); e cartunilo, piatô e vintém (Ceará).

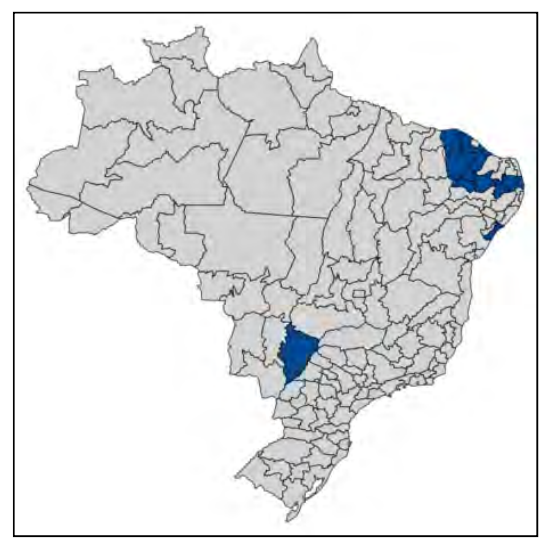

Fig. 9. Mocotó

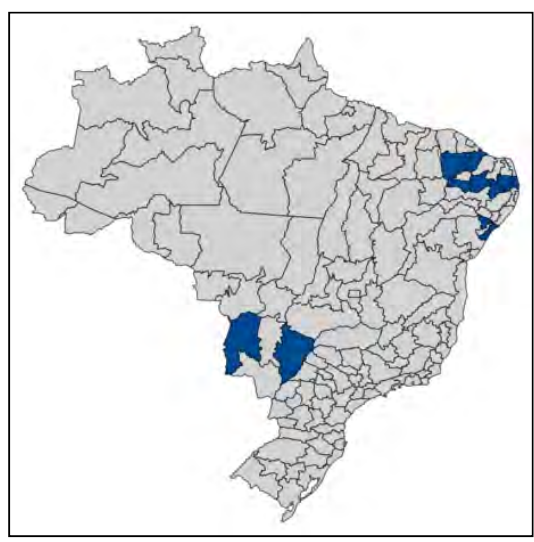

Fig. 10. Rejeito 


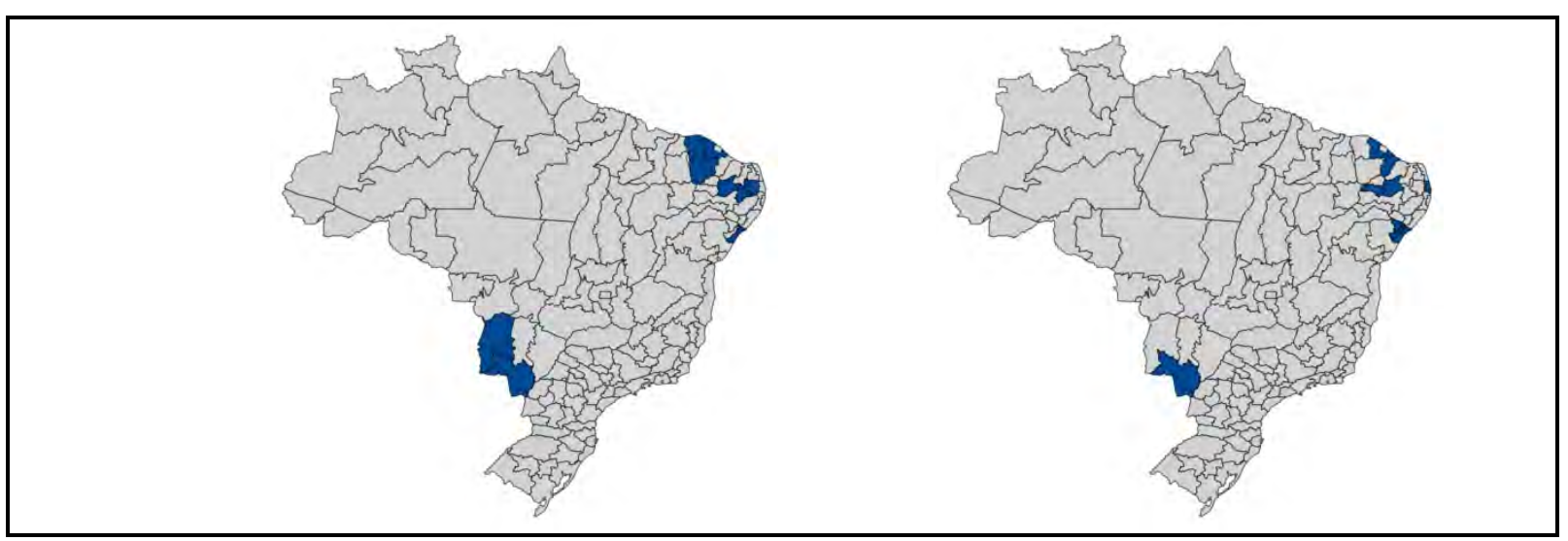

Fig. 11. Junta do pé e junta

\subsection{Análise de procesos de cambio lingüístico}

O Tesouro, ao permitir presentar conxuntamente a distribución de cada variante ou elemento léxico dentro do complexo lingüístico galego-portugués-brasileiro, convértese nun instrumento privilexiado para a abordaxe de estudos de carácter contrastivo ou centrados na análise dos procesos de variación e mudanza que teñen lugar dentro da área.

Un exemplo de estudo que se podería realizar a partir dos materiais do Tesouro constitúeo o traballo de Negro (2012) sobre as denominacións da úvula no noroeste peninsular. Neste traballo analízanse, entre outros aspectos, o cambio lingüístico a partir dos datos obtidos do $A L P I$, proxecto iniciado en 1934, do $A L E P G$ e do $A L G a$, ambos os dous atlas iniciados corenta anos despois do ALPI, e doutros materiais. Poder contar co Tesouro facilita enormemente o traballo á hora de realizar unha análise deste tipo, xa que presenta conxuntamente todos os datos sen necesidade de acudir a cada fonte individualmente.

Ademais, poder acceder a outra información datada na mesma altura que a ofrecida polos atlas, axuda a desentrañar algúns dos problemas de análise que se presentan neste tipo de estudos. Por exemplo, as denominacións para designar a úvula pinguel, pinguelo, pingallón... rexístranse no ALPI nunha área máis reducida que a que presenta o $A L G a$ corenta anos despois, a pesar de que inicialmente os datos parecían indicar que estas voces estaban a ser substituídas polo forma foránea galillo. No Tesouro encontramos datos recollidos por Schneider no ano 1938 que establecen unha área maior para pinguel e derivados que a presentada no $A L P I$, xa que recolle tamén estas variantes en Lobeira, Calvos de Randín e Xinzo de Limia, o que parece indicar que existía unha loita entre galillo e pinguel nesa altura, que acabou por gañar pinguel e os seus 
CAStro, O. / M. LiÑEIRA (eds.) (2015): Trama e urda. Contribucións multidisciplinares desde os estudos galegos, Santiago de Compostela, Consello da Cultura Galega. doi:10.17075/tucmeg.2015.

derivados. Hai que ter en conta que o cambio lingüístico non se produce en sentido único, senón que as palabras loitan por ocupar un lugar no sistema e no espazo xeográfico e nesta pelexa danse avances e retrocesos, polo que, cantos máis datos posuamos máis fácil será pescudar a dirección ou as direccións do cambio.

Por outra parte, os atlas galegos e portugueses recollen datos de un ou dous informantes maiores nunha localidade concreta, ${ }^{41}$ polo que o Tesouro permite ampliar a información destes ao ofrecer datos doutras localidades do mesmo concello e de máis informantes, o que axuda a precisar, confirmar ou mesmo corrixir as informacións de que dispoñemos ata o de agora acerca da distribución territorial de determinadas solucións. Un exemplo disto atopámolo nas designacións rexistradas nos atlas e no Tesouro para o concepto «tornecelo». No $A L G a$ só se recolle en Sobrado tobillo, porén, no Tesouro rexístrase noelo neste concello na memoria de licenciatura de López Taboada do ano 1978, isto é, só catro anos despois da realización das enquisas do $A L G a$. Neste mesmo atlas, recóllese tornecelo en Tomiño, e tobillo, en Santiago de Compostela e Touro; mais o Tesouro (Pérez 1969, 1974 e López 1969) rexistra nortello nestes tres puntos. O mesmo sucede en Aranga; no ALPI recóllese a voz nocello, pero no $A L G a$ xa non, namentres na memoria de licenciatura do ano 1967 de José Luis Couceiro si se rexistra.

Finalmente, ao estar a base do Tesouro integrada por obras máis recentes, da década dos 90 e do 2000, poderemos saber se algúns procesos de cambio continuaron ao longo do tempo ou se reverteron. No caso galego resulta especialmente interesante coñecer o avance de formas foráneas, principalmente castelanismos.

\subsection{Aproveitamentolexicográfico}

O Tesouro contribúe a preservar o patrimonio léxico ao poñer a disposición dos usuarios un gran volume de material lexicográfico procedente de fontes heteroxéneas.

A través do Tesouro podemos coñecer palabras que non están dicionarizadas nas obras lexicográficas de referencia e/ou non forman parte das compilacións do estándar. Por exemplo, das vinte e unha denominacións que se rexistran no Tesouro en Brasil co significado de «tornecelo», só se recollen no Houaiss, un dos grandes dicionarios de referencia, catro delas con este significado: mocotó, osso-do-vintém, junta e tornozelo. No Aurélio, outro gran referente

41 A tipoloxía dos informantes nos atlas brasileiros é diferente á dos galegos e portugueses, posto que a faixa etaria é máis ampla (tamén recollen información de xente nova) e sempre hai informantes dos dous sexos. En canto á escolaridade, son analfabetos, semi-analfabetos ou posúen estudos primarios, a excepción do Atlas Linguístico de Minas Gerais, que ademais recolle datos de informantes con estudos superiores. 
CAStro, O. / M. LiÑEIRA (eds.) (2015): Trama e urda. Contribucións multidisciplinares desde os estudos galegos, Santiago de Compostela, Consello da Cultura Galega. doi:10.17075/tucmeg.2015.

referente lexicográfico, tan só atopamos o termo junta e nin sequera recolle tornozelo, denominación que, como puidemos ver no mapa da súa distribución, aparece por todo Brasil.

Noutros casos encontramos o termo rexistrado, pero con outros significados, algúns relacionados con outras partes do corpo dos humanos ou dos animais. No Houaiss garrão e rejeito aparecen co significado de «jarrete», a parte de atrás dos xeonllos; machim defínese como «articulação do pé dos eqüinos»; tronco «parte mais volumosa do corpo humano, ligada à cabeça pelo pescoço, que compreende três partes (tórax, abdome e bacia) e à qual se articulam os membros; torso»; canela «parte anterior da perna entre o pé e o joelho»; calcanhar «parte posterior, arredondada, do pé humano, abaixo do tornozelo e atrás do arco do pé, cuja estrutura óssea é o osso calcâneo; talão»; e cotovelo «denominação substituída por cúbito». No Aurélio recóllense canela, cotovelo e tronco co mesmo significado que no Houaiss, e para mocotó só ofrece o sentido figurado de «perna». Joaninha, mondongo, novelo, peador, pendão e vintém rexístranse no Houaiss, pero con acepcións xa non relacionadas co corpo humano, e o mesmo sucede no Aurélio con joaninha, mondrongo, pendão e vintém.

Como puidemos verificar, nas teses incorporadas á base do Tesouro rexístranse moitas veces usos metafóricos e metonímicos dun termo, ou mesmo casos de analoxía, matices que non adoitan estar recollidos nas obras lexicográficas e que podemos coñecer grazas a este proxecto. Exemplos disto constitúenos os termos canela e calcanhar, que son usados para designar o tornecelo debido a un proceso de metonimia espacial, como explicaremos na epígrafe seguinte, e mondongo, que por un proceso metafórico pasa de designar unha pequena inchazón a designar o tornecelo. No caso de machim, por un proceso analóxico acábase usando o termo tamén para os humanos e non só para os cabalos.

Outra das posibilidades que nos ofrece a aplicación é a de realizar buscas directas de unidades complexas, que acadan unha maior visibilidade ó apareceren en pé de igualdade coas unidades monolexicais. Podemos procurar, por exemplo, abrir a boca en lema, e obteremos todas as locucións verbais rexistradas ata o momento co significado «bocexar» e a súa localización xeográfica. Este tipo de consultas facilita a realización de estudos fraseolóxicos.

Unha vantaxe máis da aplicación é a de poder facer buscas por campo semántico, o que facilita a elaboración de vocabularios temáticos e terminolóxicos. Na busca avanzada pódese seleccionar o clasificador e o dominio ou dominios lingüísticos do noso interese, por exemplo, 2.4.1, e ofrecerase unha listaxe de todos os termos clasificados nese campo, neste caso o das salinas. 
CAStro, O. / M. LiÑEIRA (eds.) (2015): Trama e urda. Contribucións multidisciplinares desde os estudos galegos, Santiago de Compostela, Consello da Cultura Galega. doi:10.17075/tucmeg.2015.

Polo tanto, o Tesouro ofrécenos infinidade de voces preparadas para ser explotadas en investigacións léxicas. Ademais, esta ferramenta axudará nos procesos de estandarización como fonte de enriquecemento do patrimonio lexical da lingua, xa que facilita formas vivas e ofrece información sobre a extensión do seu uso.

\subsection{Estudos sobre motivación semántica}

Outra das posibilidades que ofrece o Tesouro é a de analizar a motivación existente por detrás do nome asignado a un concepto. No campo semántico do corpo humano, entre os procedementos de creación léxica, debemos destacar o uso da metáfora, proceso semántico mediante o cal concibimos unha cousa en termos doutra e que ten como función primaria a comprensión. Segundo Lakoff e Johnson, «la mayor parte de nuestro sistema conceptual ordinario es de naturaleza metafórica» (2009: 40); de feito, nas designacións de partes do corpo humano atopámonos con moitas voces de natureza metafórica como nobelo, mondongo, campaíñ...

É tamén frecuente no campo léxico do corpo humano, como xa sinalamos, que se dean procesos de metonimia espacial, é dicir, que haxa confusión á hora de designar partes do corpo próximas entre si, como sucede con canela «óso máis longo e groso dos dous que unen o xeonllo co pé» e calcañar «parte inferior do talón», voces que tamén designan o nocello nalgúns puntos do territorio galego-portugués-brasileiro.

\section{CODA}

No presente artigo tratamos de amosar algunhas das moitas posibilidades de aplicación que posúe o Tesouro do léxico patrimonial galego e portugués para a análise do espazo lingüístico galego e portugués (portugués europeo e portugués brasileiro). Ao poñer a disposición dos usuarios unha cantidade inxente de material dialectal, moitas veces inédito ou de difícil acceso, o Tesouro facilita a realización de estudos de diversa índole, sincrónicos e diacrónicos, en diversas áreas.

O Tesouro, ao presentar conxuntamente a distribución de cada variante dentro do complexo lingüístico galego-portugués-brasileiro, grazas á cartografía xerada automaticamente pola aplicación de consulta, permite analizar a distribución das variantes existentes para designar un concepto dentro deste complexo. De feito, puidemos verificar como a existencia de «descontinuidades» na distribución territorial de certas voces permiten, por 
CAStro, O. / M. LiÑEIRA (eds.) (2015): Trama e urda. Contribucións multidisciplinares desde os estudos galegos, Santiago de Compostela, Consello da Cultura Galega. doi:10.17075/tucmeg.2015.

exemplo, deitar luz sobre casos de polixénese ou de migración de palabras. Noutras ocasións atopamos denominacións comúns a Galicia e Portugal que forman un contínuum entre estas dúas áreas. Puidemos tamén comprobar como a distribución espacial obriga a desbotar (ou cando menos poñer en dúbida) algunhas hipóteses etimolóxicas e, polo tanto, a lanzar outras hipóteses sobre os procesos diacrónicos que se produciron.

Tamén é o Tesouro un instrumento privilexiado para a abordaxe de estudos de carácter contrastivo ou centrados nos procesos de variación e mudanza existentes na área. No corpo do traballo amosamos como en moitas ocasións o Tesouro permite confirmar, ampliar ou contrastar a información ofrecida polos atlas lingüísticos, polo que se converte nunha valiosa axuda á hora de analizar procesos de cambio lingüístico.

Ademais, demostramos a utilidade da ferramenta para a lexicografía, xa que recolle palabras non dicionarizadas (cartunilo «tornecelo») e novos significados de voces si rexistradas nos dicionarios (rejeito só aparece no dicionario Houaiss co significado de «jarrete» e non co de «tornecelo»). Facilita igualmente a realización de estudos fraseolóxicos, ao presentar as unidades complexas en pé de igualdade coas monolexicais, e a elaboración de vocabularios temáticos e terminolóxicos, ao poder realizarse consultas por campo semántico.

Por último, vimos como na base do Tesouro se rexistran moitas veces usos metafóricos e metonímicos dun termo (canela e calcanhar «tornecelo»), matices que non adoitan estar presentes nas obras lexicográficas, o que posibilita a realización de traballos sobre motivación semántica. Incluso verificamos como algunhas das voces de natureza metonímica ou metafórica son comúns aos tres dominios lingüísticos.

Confiamos en que as características e posibilidades de consulta deste corpus o convertan nunha ferramenta útil para a realización de múltiples estudos centrados no léxico patrimonial galego e portugués. 
CAStro, O. / M. LiÑEIRA (eds.) (2015): Trama e urda. Contribucións multidisciplinares desde os estudos galegos, Santiago de Compostela, Consello da Cultura Galega. doi:10.17075/tucmeg.2015.

\section{REFERENCIAS BIBLIOGRÁFICAS}

ALEAç = SARAMAGO, João (coord.) (2001-): Atlas Linguístico-Etnográfico dos Açores, Lisboa, Centro de Linguística da Universidade de Lisboa.

ALECE = BESSA, José Rogério Fonetele (org.) (2010): Atlas Linguístico do Estado do Ceará, Fortaleza, Universidade Federal do Ceará.

ALEPG = SARAMAGO, João (dir.): Atlas Linguístico-Etnográfico de Portugal e da Galiza, Lisboa, Centro de Linguística da Universidade de Lisboa [material inédito].

ALGa $=$, Constantino / Antón SANTAMARINA (eds.) (1990-): Atlas Linguístico Galego, A Coruña, Fundación Pedro Barrié de la Maza.

ALISPA = RAZKY, Abdelhak (2004): Atlas linguístico sonoro do Pará, Belém, CAPES / Universidade Federal do Pará.

ALLP = VITORINO, Gabriela (1987): Atlas linguístico do litoral português: fauna e flora, 2 vols. [inédito].

ALMESEMT = CUBA, Marigilda Antônio (2009): Atlas Linguístico da Mesorregião Sudeste de Mato Grosso, dissertação de mestrado em Estudos de Linguagens, Universidade Universidade Federal de Mato Grosso do Sul.

ALMS = DERCIR, Pedro de Oliveira (org.) (2007): Atlas linguístico de Mato Grosso do Sul, Campo Grande-MS, Universidade Federal de Mato Grosso do Sul.

ALPB = ARAGÃO, Maria do Socorro Silva de / Cleusa Bezerra de MENEZES (1984): Atlas linguístico da Paraíba, vols. 1 e 2, Brasília, Conselho Nacional de Desenvolvimento Científico e Tecnológico / Universidade Federal da Paraíba.

ALPI = TOMÁS NAVARRO, Tomás (ed.) (1931-1954): Atlas lingüistico da Península Ibérica [cadernos inéditos].

ALPR = AGUILERA, Vanderci de Andrade (org.) (1994): Atlas linguístico do Paraná, Curitiba, Imprensa Oficial do Estado.

ALS = FERREIRA, Carlota da S. et al. (1987): Atlas linguístico de Sergipe, Salvador, Universidade Federal da Baía / Fundação Estadual de Cultura de Sergipe.

ÁlVAREZ, Rosario (1974): Notas lingüísticas e etnográficas de Ramirás, memoria de licenciatura, Universidade de Santiago de Compostela.

ÁLVAREZ, Rosario / Xosé Afonso ÁLVAREZ / João SARAMAGO / Xulio SOUSA (2009): «Presentación de un corpus digital de léxico tradicional: Tesouro do léxico patrimonial galego e portugués», Fonetică şi Dialectologie, 28, 5-19.

ÁLVAREZ, Rosario (coord.): Tesouro do léxico patrimonial galego e portugués, Santiago de Compostela, Instituto da Lingua Galega (http://ilg.usc.es/tesouro/) [última consulta: xullo, 2014].

ÁLVAREZ, Xosé Afonso / Xulio Sousa (2013): «The Tesouro do léxico patrimonial galego e portugués. A Galician and Portuguese Word Bank», Dialectologia, Special issue IV, 5-24.

ÁlVAREZ, Xosé Afonso (2012): «O léxico do namoro no Tesouro Dialectal Português (TEDIPOR)», XXVII Encontro Nacional da APL. Textos seleccionados, Lisboa, Associação Portuguesa de Linguística, 540-554.

AMORIM, Laerte Carpena de (1988): As salinas de Cabo Frio, tese de doutorado, Universidade Federal do Rio de Janeiro.

BLANCO, Franscico (coord.) (2012): O palabreiro portexo (http://www.furmientu.org/08Vocabularios2012/03VocabulariuPortexo.pdf) [última consulta: decembro, 2013]. 
CAStro, O. / M. LiÑEIRA (eds.) (2015): Trama e urda. Contribucións multidisciplinares desde os estudos galegos, Santiago de Compostela, Consello da Cultura Galega. doi:10.17075/tucmeg.2015.

BORGES, Naír Odete da Câmara (1954): Influência anglo-americana no falar do povo micaelense, dissertação de licenciatura, Universidade de Coimbra [ed. de id. (1960): Influência anglo-americana no falar da ilha de S. Miguel (Açores). Suplemento II da Revista Portuguesa de Filologia].

CARRANCHO, Maria Licínia Sarrico dos Santos (1969): A linguagem dos pescadores de Lagos, dissertação de licenciatura, Universidade de Lisboa.

CASTRO, Xosé Manuel (1986): O galego en Queizán (O Corgo), memoria de licenciatura, Universidade de Santiago de Compostela.

CHAO, Antonio: Codosedo. Sarreaus (http://www.geocities.ws/codosedo/index-2.html) [última consulta: marzo, 2012].

COROMINES, Joan / José Antonio PASCUAL (1989²): Diccionario crítico etimológico castellano e hispánico, Madrid, Gredos.

COSTA, Eliane Oliveira da (2012): Glossário da cerâmica artesanal do distrito de Icoaraci $($ Belém/PA), dissertação de mestrado, Belém, Universidade Federal do Pará.

COUCEIRO, José Luis (1967): Vocabulario de Feás, memoria de licenciatura, Universidade de Santiago de Compostela.

DOMÍNGUEZ, Helena (coord.) (2012): Dicionario de ausencias (http://illadearousa.blogspot.com.es/2009/05/algunhas-das-palabras-que-usan-cotioas.html) [última consulta: febreiro, 2012].

FERREIRA, Aurélio Buarque de Holanda: Dicionário do Aurélio (http://www.dicionariodoaurelio.com/) [última consulta: xullo, 2014].

GONZÁLEZ, Manuel (2002): «A dialectoloxía ó servicio do estudo da estratigrafía do léxico», en Rosario Álvarez / Francisco Dubert / Xulio Sousa (eds.), Dialectoloxía e léxico, Santiago de Compostela, Instituto da Lingua Galega / Consello da Cultura Galega, 29-40.

HOUAISS, António / Mauro DE SALLES VILLAR / Francisco Manoel DE MELLO FRANCO (dirs.) (2007): Dicionário Eletrônico Houaiss da Língua Portuguesa, Rio de Janeiro, Objetiva.

LAKOFF, George / Mark JOHNSON (2009): Metáforas de la vida cotidiana, Madrid, Cátedra.

LÓPEZ Xavier / Gabriel FERNÁNDEZ / Eva FERNÁNDEZ (2011): O galego de Zamora. Volvemos co vocabulario de Brumoso (http://abrumoso.blogspot.com.es/20 11/11/-volvemos-co-vocabulario-de-brumoso.html) [última consulta: abril, 2012].

LÓPEZ, Carme (1978): El habla de la comarca de Sobrado de los Monjes, memoria de licenciatura, Universidade de Santiago de Compostela.

LÓPEZ, Jesús (1969): Vocabulario de Novefontes. Contribución a un estudio lingüístico, memoria de licenciatura, Universidade de Santiago de Compostela.

MAIA, Maria Lúcia Borba e (1965): O falar da ilha Terceira, dissertação de licenciatura, Universidade de Lisboa.

MORANDEIRA, Josefa (1969): El habla de Lage, memoria de licenciatura, Universidade de Santiago de Compostela.

NEGRO ROMERO, Marta (2012): «Names for the Uvula in the West of the Iberian Peninsula: a Geolinguistic Approach», Dialectologia. Special issue III (http://www.publicacions.ub.edu/revistes/dialectologiaSP2012/).

NETTO, Maria Teresa de Mendonça Lino (1945): A linguagem dos pescadores e lavradores do concelho de Vila do Conde, dissertação de licenciatura, Universidade de Coimbra [ed. id. (1949): A linguagem dos pescadores e lavradores do concelho de Vila do Conde. Separata de Revista Portuguesa de Filologia, vols. I e II]. 
CAStro, O. / M. LiÑEIRA (eds.) (2015): Trama e urda. Contribucións multidisciplinares desde os estudos galegos, Santiago de Compostela, Consello da Cultura Galega. doi:10.17075/tucmeg.2015.

PÉREZ, Ma Jesús (1969): Vocabulario de Goián, memoria de licenciatura, Universidade de Santiago de Compostela.

RÍOS PANISSE, $\mathrm{M}^{\mathrm{a}}$ del Carmen (1977): Nomenclatura de la flora y fauna marítimas de Galicia. Vol. 1. Invertebrados y peces, con anotaciones etimológicas por Antonio Santamarina, Verba. Anuario Galego de Filoloxía, anexo 7.

RÍOS PANISSE, $\mathrm{M}^{\mathrm{a}}$ del Carmen (1983): Nomenclatura de la flora y fauna maritimas de Galicia. Vol. 2. Mamiferos, aves y algas, Verba. Anuario Galego de Filoloxía, anexo 19.

RODRÍGUEZ LAGO, Ma Carmen (1974): Léxico dialectal y costumbres de Porto, memoria de licenciatura, Universidade de Santiago de Compostela.

SCHNEIDER, Hans (1938): «Studien zum Galizischen des Limiabeckens (Orense-Spanien) Lautlehre, Formenlehre, Vokabular», VKR XI, 67-145.

SOZIM, Miriam Martins (1991): A linguagem do apicultor nas regiões de Ponta Grossa e Prudentópolis: aspectos lexicais e fonéticos, dissertação de mestrado, Assis-SP, Universidade Estadual Paulista. 